\title{
THE EFFECT OF HIGH SPEED LASER TRIMMING ON ACCURACY AND STABILITY OF THICK FILM RESISTORS
}

\author{
RENÉ E. COTÉ \\ E. I. du Pont de Nemours \& Company, Electronic Materials Division - Photo Products Department, \\ Chestnut Run, Wilmington, Delaware 19898
}

\begin{abstract}
Many recommendations have been made on the proper operating conditions for the laser trimming process. In general these recommendations have centered on accuracy, precision or throughput. In some instances, these have appeared to be mutually exclusive. If one wanted accuracy and precision, one had to sacrifice trimming speed and, therefore, throughput.

It has been reported that $40 \%$ of the processing cost of a thick film resistor network is due to laser trimming. To continue to make these networks commercially attractive, the manufacturers of laser trimming systems have addressed themselves to the problem of providing suitable cuts at higher and higher trimming speeds.

It is important for the user of such a system to understand the basics of the trimming process and to have an appreciation for the new factors which will affect the performance characteristics of laser trimmed thick film resistors. This paper summarizes the previous work as it relates to present technology. It then attempts to develop new guidelines for high speed laser trimming.
\end{abstract}

\section{INTRODUCTION}

The overall subject of high speed laser trimming increases in importance as more emphasis is placed on the manufacture of resistor networks and high volume thick film hybrid circuits. It has been estimated that the laser trimming process is $40 \%$ of the cost of processing a thick film resistor network. This immediately leads the cost-reduction minded engineer to study the entire laser trimming process, especially high speed trimming.

High speed laser trimming should immediately be distinguished from high throughput. High throughput can be achieved by means other than high speed. Handling and testing times are probably more significant factors in the overall trimming process. Increased automation in parts handling, as well as the use of larger substrates containing multiple circuits per substrate, will increase throughput independent of trimming speed.

Before any logical discussion of high speed laser trimming can proceed, it is worthwhile to review some basic definitions, examine the differences which may exist between the presently available systems and, also set some meaningful guidelines.

A basic laser trimming system consists of a laser, a computer control system, a resistance probing and measuring system, and a mechanism to position the laser beam and move it from point to point across the substrate surface.

\section{LASER}

At the present time, most of the trimming systems use a neodymium doped yttrium àluminum garnet (Nd-YAG) laser head which is comprised of an elliptical gold plated cavity in which the Nd-YAG laser rod is excited by a DC Krypton arc lamp. The amount of laser energy which results is primarily determined by adjustment of the arc lamp current.

An acoustic Q-switch is added to the system to produce giant pulse operation which is required to obtain the necessary peak pulse energy to vaporize the thick film material. Q-switched operation provides the ability to attain peak power pulses in excess of $25 \mathrm{KW}$ at pulse repetition rates of 1 to $50 \mathrm{kHz}$. Table I shows a comparison of two commonly used laser systems.

A block diagram of the laser system is shown in Figure 1. A cross-section of the laser cavity is shown in Figure 2. The elliptical shape assures that all of the light, emitted from the lamp, will be concentrated on the laser rod for maximum efficiency.

The laser rod can be activated to produce a fundamental output which gives a single spot, referred 
TABLE 1

\begin{tabular}{lrr}
\hline & Laser A & \multicolumn{1}{c}{ Laser B } \\
\hline Multimode power & $30 \mathrm{~W}$ & $50 \mathrm{~W}$ \\
TEM $_{0,0}$ power & $4 \mathrm{~W}$ & $6-8 \mathrm{~W}$ \\
Multimode beam dia. & $4.0 \mathrm{~mm}$ & $4.0 \mathrm{~mm}$ \\
TEM $_{0,0}$ beam dia. & $1.5 \mathrm{~mm}$ & $1.5 \mathrm{~mm}$ \\
Rep rates & $1-50 \mathrm{kHz}$ & $1-50 \mathrm{kHz}$ \\
Rod size & $4 \times 50 \mathrm{~mm}$ & $4 \times 75 \mathrm{~mm}$ \\
\hline
\end{tabular}

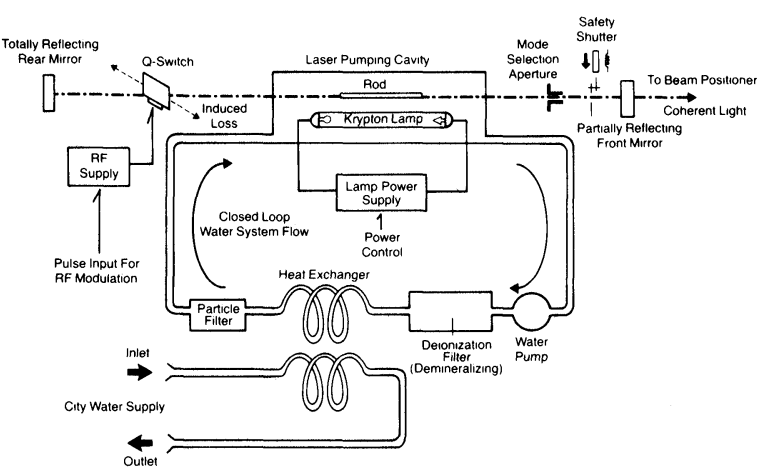

FIGURE 1 Laser system block diagram.

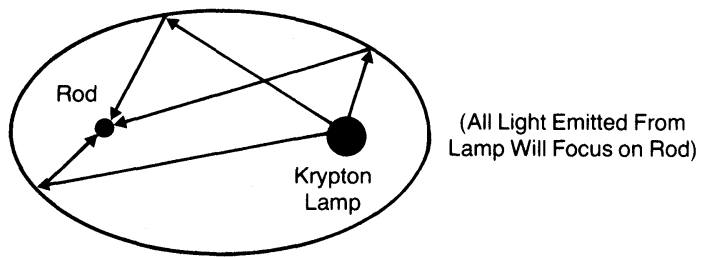

FIGURE 2 Cross-section of elliptical laser pumping cavity.

to as $\mathrm{TEM}_{0,0}$ mode. By increasing the arc lamp current the beam may diverge from single spot operation into multimode operation, such as $\mathrm{TEM}_{0,1}$ and $\mathrm{TEM}_{1,0}$. Figure 3 shows these three laser spot shapes. For precision trimming, $\mathrm{TEM}_{0,0}$ is the preferred mode of operation; however, multimode operation has been used successfully in many laser trimming processes.

We have introduced two important laser trimming parameters - PEAK POWER and PULSE REPETITION RATE. At this point, it is useful to introduce two more laser terms - AVERAGE POWER and PULSE WIDTH. Average power is one of the common set-up parameters which is specified for

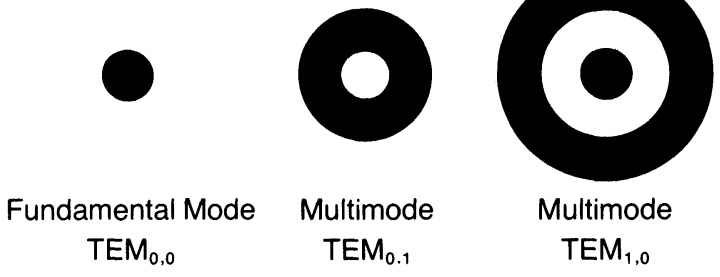

FIGURE 3 Laser spot shapes.

the manufacturing operation. It is defined as the time-average of the peak power and is easier to measure than peak power. The second term, pulse width, varies somewhat with pulse repetition rate and is also referred to as Q-rate or pulse frequency.

Figures 4-7 show the relationships which exist between peak pulse power, average power and pulse width as a function of pulse repetition rate. Figures 4

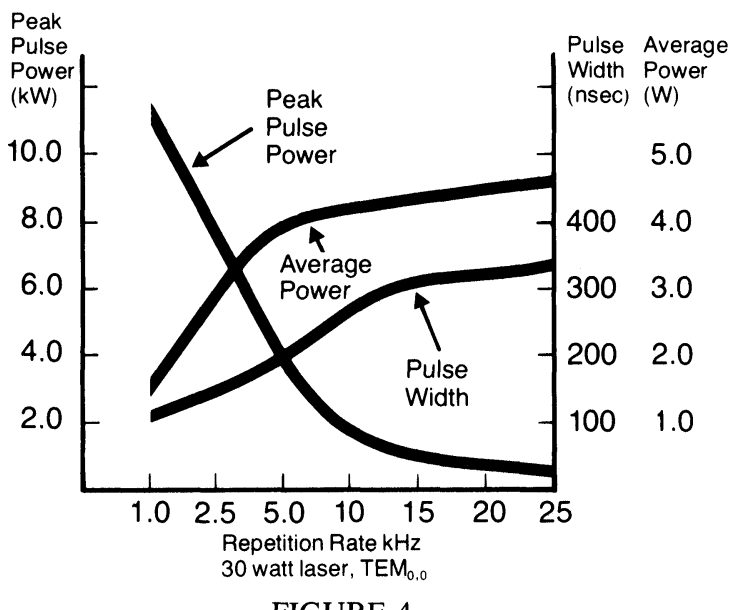

FIGURE 4.

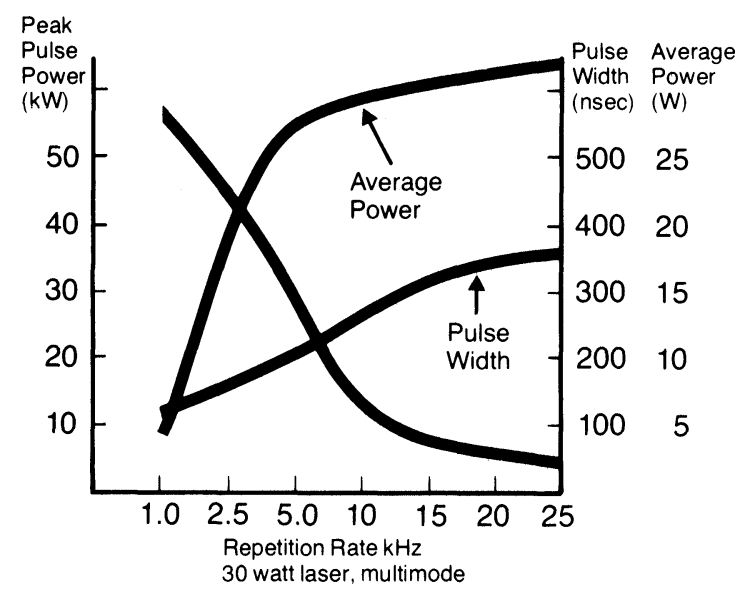

FIGURE 5. 


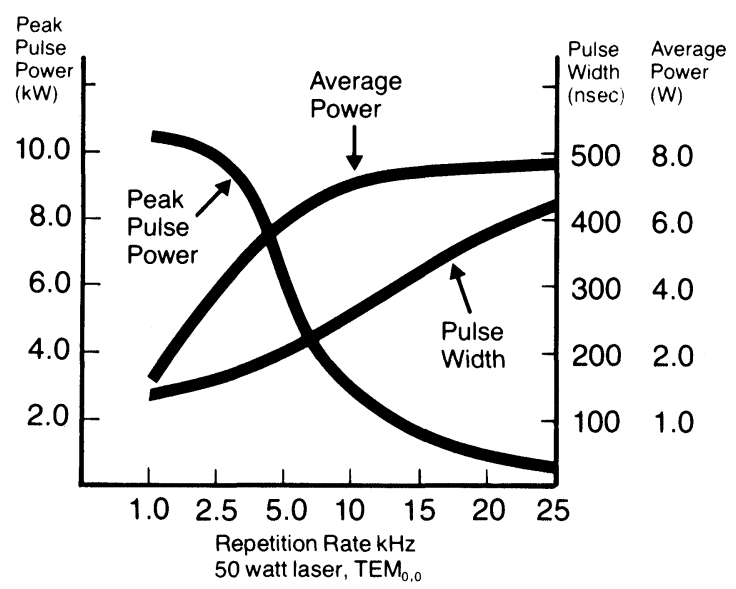

FIGURE 6.

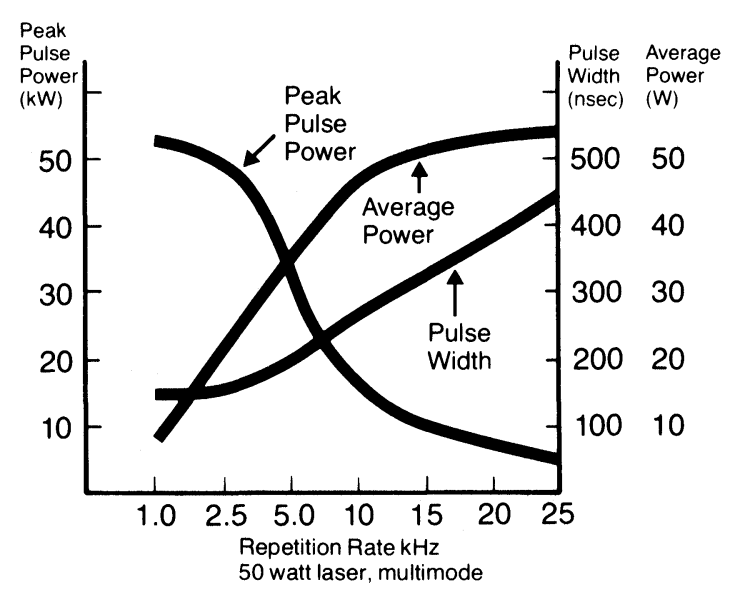

FIGURE 7.

and 5 are given for the $3 \mathrm{~W}$ laser while Figures 6 and 7 are those for the $50 \mathrm{~W}$ laser. For maximum resistor stability the peak pulse power should be maximized with relation to the average power. This assures that more of the laser energy per pulse is available for the removing of material and less energy is lost in undesired heating of adjacent resistor and substrate material.

\section{BEAM POSITIONER}

Two basic methods are presently used to position the laser beam and move it from point to point across the substrate. One method employs galvanometer driven " $X$ " and " $Y$ " mirrors as depicted in Figure 8. This method is very responsive and has accelerations of up

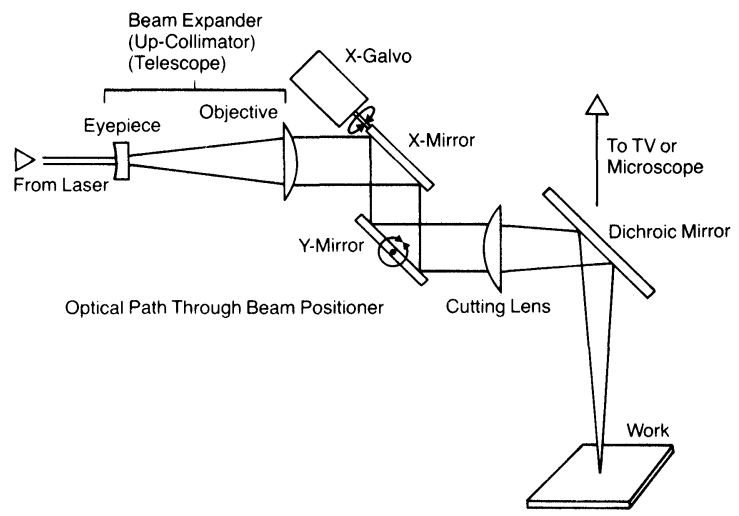

FIGURE 8 Galvanometer driven " $\mathrm{X}$ " + "Y" mirrors.

to 200G's. The other consists of " $X$ " and "Y" arms activated by directly-coupled voice coil linear actuators. This method is shown pictorially in Figure 9. The linear actuators have high positional accuracy and repeatability and accelerate up to approximately 20G's.

On the basis of acceleration alone, the galvanometer driven mirrors appear capable of higher trimming speeds, although it may be argued that the throughput of either system can be optimized to be quite similar.

Incorporated into the beam positioner is a focusing device to concentrate the beam power onto the surface of the thick film material. The focusing lens of typical thick film optics have a rating of $\mathrm{f} 30$ which results in a beam waist theoretically capable of achieving a $30 \mu \mathrm{m}$ spot size. Practically, however, the minimum spot size is closer to $50 \mu \mathrm{m}$. The depth of field for these optics is

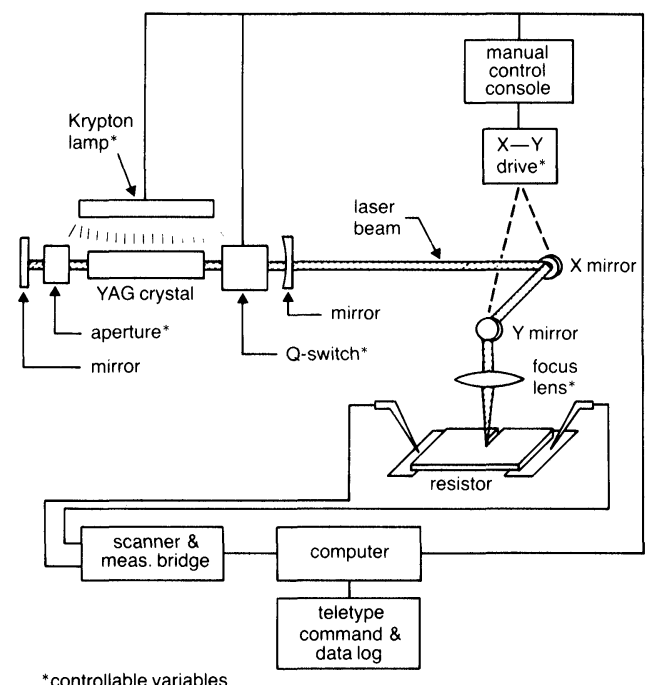

FIGURE 9. 
approximately $400 \mu \mathrm{m}$. Thus, it is important to refocus the beam when going from one substrate thickness to another.

\section{MECHANICS OF THE LASER CUT}

The subject of how laser pulses are produced, positioned and then moved over the substrate surface has been discussed. Now the mechanics of laser cuts should be considered. Making clean laser cuts begins with properly processed thick films. Shah and Berrin ${ }^{10}$ of Bell Telephone Laboratories have discussed the importance of controlling film thickness. Laser trimming is a physical process concerned with removing material by vaporization. The integrity of the remaining film is dependent on the cleanliness of the cut and the amount of damage incurred. Excessive damage results when too much power, at less than vaporization levels, is allowed to affect a given area. It therefore becomes important to carefully control the absolute peak energy of each pulse and the speed at which they travel across the surface of the material being removed.

Figure 10 shows how a typical laser cut may be produced at two different speeds or even at the same speed for two different pulse rates. Figure 10a shows a cut made with an overlap of $50 \%$. This is considered the minimum overlap which should be used to produce uniform, high quality cuts. Figure $10 \mathrm{~b}$ shows less than $10 \%$ overlap. This can produce ragged, irregular cuts, often of insufficient depth.

Overlap also becomes an important factor in the accuracy or precision which can be obtained from the laser trimming process. If an overlap of $50 \%$ is being used and the pulse has a diameter of $50 \mu \mathrm{m}$, each pulse takes a $25 \mu \mathrm{m}$ bite out of the resistor being trimmed. If small resistors are being trimmed to value, the accuracy is very dependent on the extent of trimming.

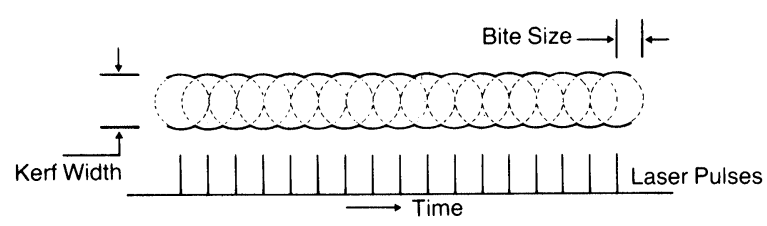

FIGURE 10a.

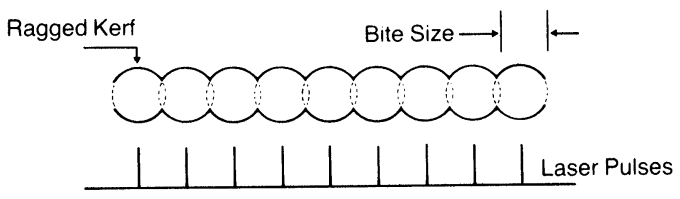

FIGURE 10b.

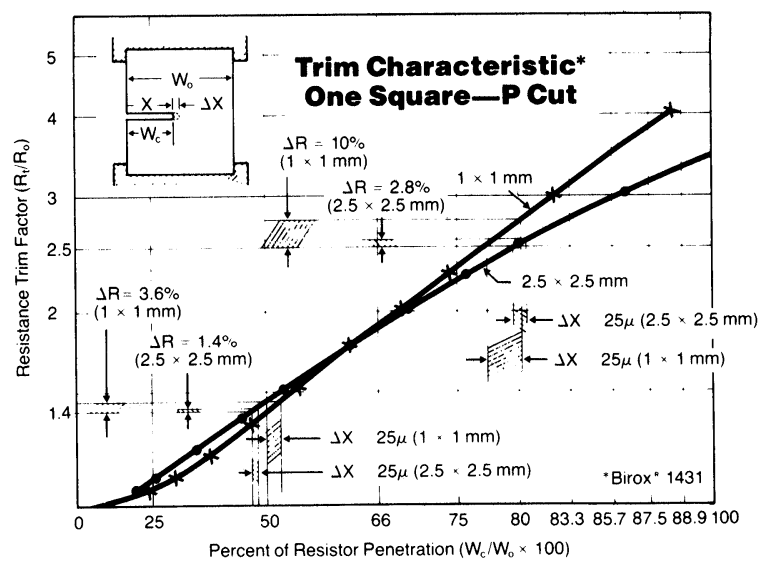

FIGURE 11

Figure 11 shows this graphically. It compares a $1 \mathrm{~mm}^{2}$ resistor to a $2.5 \mathrm{~mm}^{2}$ resistor. It shows that when a $1 \mathrm{~mm}^{2}$ resistor has its value raised $1.4 \times$ the fired value, one extra pulse resulting in $25 \mu \mathrm{m}$ extension of the cut changes the value $3.6 \%$. When the value is raised $2.5 \times$ the initial fired value, the same pulse will change the value approximately $10 \%$. These changes become $1.4 \%$ and $2.8 \%$ for a $2.5 \mathrm{~mm}^{2}$ resistor. This presumes that each pulse removes all the resistor material directly beneath it.

When high speed and high precision are equally important, it is necessary to take all factors into consideration. The geometry must be selected to accommodate the desired end results. The bite size must be chosen to be compatible with the trimming speed used. In all cases, it is assumed that the measurement system is capable of fast accurate tracking.
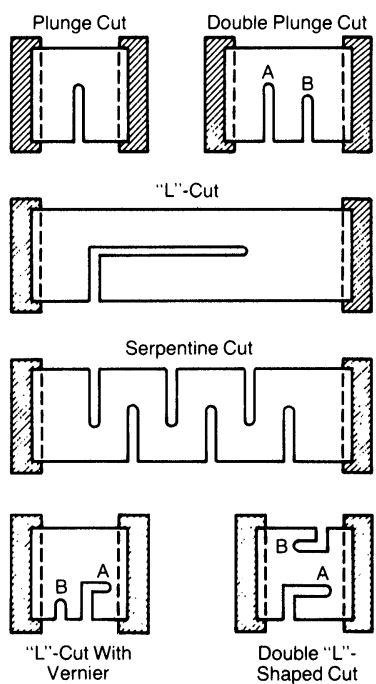

FIGURE 12 Laser cutting techniques. 
There are several ways of cutting a resistor during the laser trimming operation. Figure 12 illustrates six methods of trimming square and rectangular geometries. The plunge cut is the fastest and most used configuration for reasonable accuracy and stability. When greater initial accuracy is required, the " $L$ " cut offers more advantage at only a slight decrease in speed. All of the multiple cuts except the serpentine are usually made with a delay between the first cut (A) and the second cut (B). The amount of delay varies from situation to situation, but usually the first cut is made in all of the resistors on the substrate and then, immediately after, the second cut is made without removing the part from the system. The first cut adjusts resistance value to $\sim 98 \%$ of the target value; the final adjustment to the desired cut-off value is completed during the second cut.

\section{OPTIMIZING FOR HIGHER TRIMMING SPEEDS}

In order to trim at higher speeds, the laser system must achieve the desired speed in the prescribed amount of time. In other words, it must generate the necessary number of pulses per unit of linear travel at that speed, and it must deliver the necessary amount of peak pulse energy to remove material.

In order to be able to talk more objectively about laser trimming parameters, other basic laser trimming terms must be defined:

$$
\begin{aligned}
& \mathrm{P}=\text { Average Beam Power (Q-Switched Mode) } \\
& \mathrm{Q}=\text { Pulse Frequency } \\
& \mathrm{S}=\text { Trimming Speed } \\
& \text { Linear Energy Density (LED) }=\mathrm{P} / \mathrm{S}
\end{aligned}
$$

(Joule/mm)

$$
\text { Linear Pulse Density }(\text { LPD) }=\mathrm{Q} / \mathrm{S}
$$$$
\text { (pulse/mm) }
$$$$
\text { Cutting Power }(\mathrm{CP})=\text { LED } \times \text { LPD Joule }
$$$$
\text { (pulse } / \mathrm{mm}^{2} \text { ) }
$$

Having defined the term cutting power, experiments were run using $\mathrm{Du}$ Pont Series 17 resistor compositions. Low ohm material $(100 \Omega / \square)$ and high ohm material $(10 \mathrm{~K} \Omega / \square)$ were cut at various average beam powers, pulse frequencies and trim speeds. The insulation resistance of a $1 \mathrm{~mm}^{2}$ resistor, which was cut completely through, was measured at $200 \mathrm{~V}$. It was determined that an initial insulation resistance greater than $2 \times 10^{9}$ ohms was necessary to produce a stable cut. Figures 13 and 14 show the graphical results of this study.

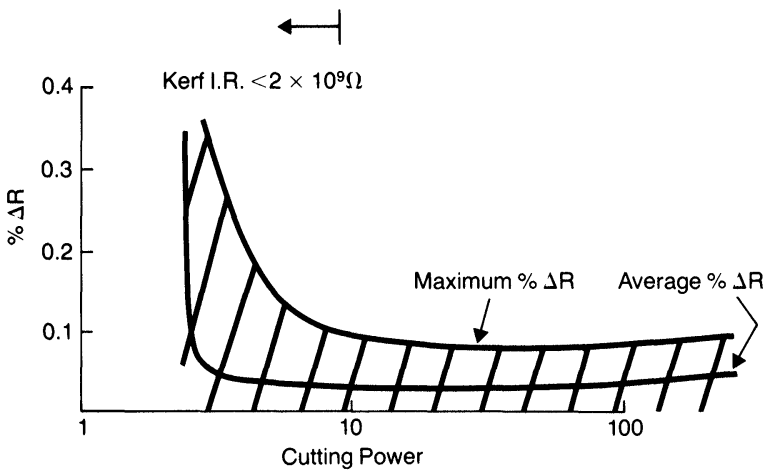

FIGURE 13 Parametric trim study $-1000 \Omega / \square 100$ hour post trim $\% \Delta \mathrm{R}$.

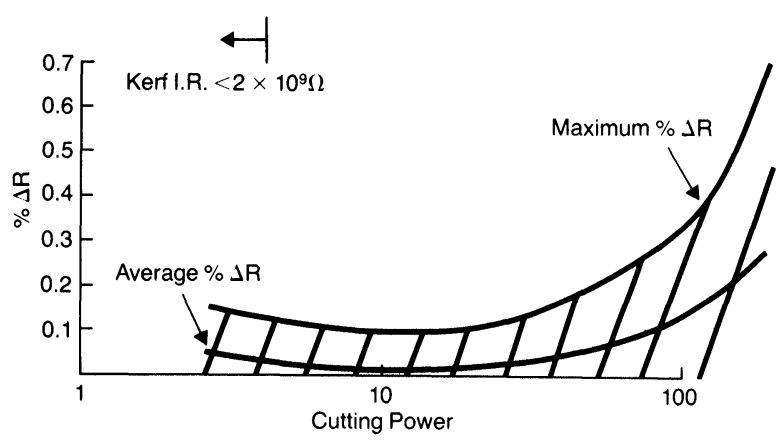

FIGURE 14 Parametric trim study $-10 \mathrm{~K} \Omega / \square 100$ hour post trim $\% \Delta \mathrm{R}$.

For the $100 \Omega / \square$ material, a cutting power of 10 joule pulse $/ \mathrm{mm}^{2}$ was necessary; for the $10 \mathrm{~K} \Omega / \square$ material, necessary cutting power was reduced to 6 joule pulse $/ \mathrm{mm}^{2}$. Thus, a cutting power of 15 joule pulse $/ \mathrm{mm}^{2}$ is sufficient to produce trimmed resistors of either type with good end of life stability. If one uses a minimum of 120 pulses per $\mathrm{mm}$ to assure clean cuts, it then becomes possible to calculate the pulse frequency and average power which must be used to achieve a desired trimming speed.

Figure 15 shows the shape of the acceleration curve for the linear actuator type of beam positioner. At $100 \mathrm{~mm} / \mathrm{sec}$ trimming speed, $0.4 \mathrm{~mm}$ are required to come up to full trimming speed and the same $0.4 \mathrm{~mm}$ to decelerate to 0 velocity. If a distance limit stop is used, $0.4 \mathrm{~mm}$ are required to come to full speed and approximately $1 \mathrm{~mm}$ to decelerate. This limits the overall speed achieved during the trimming operation for this type of beam positioner. A method of increasing throughput time is to come up to acceleration and trim all resistors without decelerating 

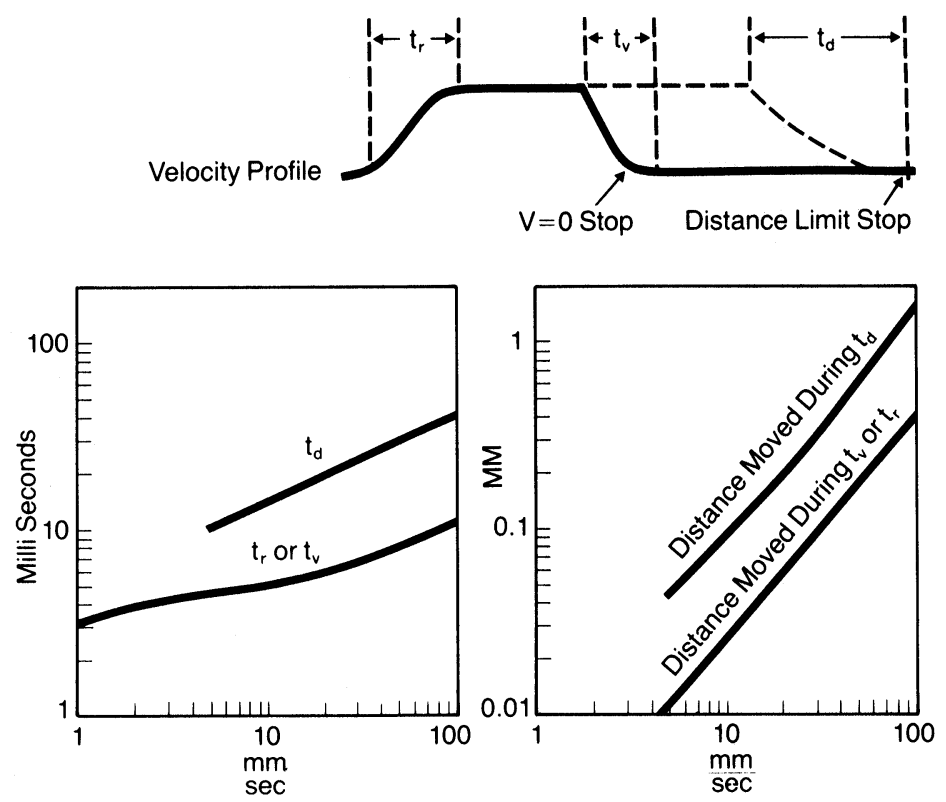

FIGURE 15 Velocity profile for direct-coupled voice linear actuator.

by turning the laser on and off as one goes from resistor to resistor without stopping.

In the case of average pulse power and pulse frequency, the commonly used lasers are currently limited to 50 watts multimode operation or $8 \mathrm{~W} \mathrm{TEM}_{0,0}$ and $50 \mathrm{kHz}$ maximum switch frequency.

Keeping these stated limitations in mind and recalling the equation for cutting power, it is possible to calculate the average power and pulse frequency required to produce satisfactory laser cuts at various laser trimming speeds. For Series 17 resistors, we can calculate these parameters for cutting powers of 6,10

\section{TABLE II}

Cutting power $=$ LPD $\times$ LED $=Q / S \times P_{\text {avg }} / S$

where $P_{\text {avg }}=$ joules $/ \mathrm{sec}$

(1) $Q=120 \mathrm{~S}(\mathrm{~Hz})$

(2) $P_{\text {avg }}=0.05 \mathrm{~S}$ (watts) at cutting power 6

$=0.083 \mathrm{~S}$ (watts) at cutting power 10

$=0.125 \mathrm{~S}$ (watts) at cutting power 15

\begin{tabular}{lllll}
\hline & \multicolumn{4}{c}{ power (watts) } \\
\cline { 3 - 5 } $\begin{array}{llll}\text { Speed } \\
(\mathrm{mm} / \mathrm{sec})\end{array}$ & $\begin{array}{l}\text { Frequency } \\
(\mathrm{kHz})\end{array}$ & $\mathrm{CP}=6$ & $\mathrm{CP}=10$ & $\mathrm{CP}=15$ \\
\hline 10 & 1.2 & 0.5 & 0.83 & 1.25 \\
56 & 6 & 2.5 & 4.15 & 6.25 \\
100 & 12 & 5 & 8.3 & 12.5 \\
500 & 60 & 25 & 41.5 & 62.5 \\
\hline
\end{tabular}

and 15 joule pulse $/ \mathrm{mm}^{2}$. The results are shown in Table II. Recall that 120 pulses per $\mathrm{mm}$ are required to assure complete cutting.

These calculations show that to operate in $\mathrm{TEM}_{0,0}$ mode, the practical speed limit is approximately $100 \mathrm{~mm} / \mathrm{sec}$. If higher speeds are required, multimode operation must be accepted. Refer to Charts 4-7 for specifics. If one is satisfied with a minimum of $50 \%$ overlap which is 40 pulses per mm, instead of 120 , then the conditions are shown in Table III.

It still appears as though the practical trimming speed is $100 \mathrm{~mm} / \mathrm{sec}$ to maintain $\mathrm{TEM}_{0,0}$ mode.
Cutting power $=$ LPD $\times$ LFD $=Q / S \times P_{\text {avg }} / S$ where $P_{\text {avg }}=$ joules $/ \mathrm{sec}$

(1) $Q=80 \mathrm{~S}(\mathrm{~Hz})$

(2) $P_{\text {avg }}=0.07 \mathrm{~S}$ (watts) at cutting power 6 $=0.125 \mathrm{~S}$ (watts) at cutting power 10 $=0.185 \mathrm{~S}$ (watts) at cutting power 15

\begin{tabular}{lllll}
\hline & & \multicolumn{3}{l}{ power (watts) } \\
\cline { 3 - 5 } $\begin{array}{l}\text { Speed } \\
(\mathrm{mm} / \mathrm{sec})\end{array}$ & $\begin{array}{l}\text { Frequency } \\
(\mathrm{kHz})\end{array}$ & $\mathrm{CP}=6$ & $\mathrm{CP}=10$ & $\mathrm{CP}=15$ \\
\hline 10 & 0.8 & 0.75 & 1.25 & 1.85 \\
50 & 4.0 & 3.75 & 6.25 & 9.25 \\
100 & 8.0 & 7.5 & 12.5 & 18.5 \\
500 & 40 & 37.5 & 62.5 & 92.5 \\
\hline
\end{tabular}




\section{CONCLUSIONS}

The entire subject of high speed laser trimming must be considered very carefully so that adequate accuracy and stability of the trimmed resistors are maintained. The laser system must be capable of achieving the necessary peak pulse power and pulse frequency necessary to remove the material cleanly. The beam positioner must be capable of achieving the necessary acceleration and running speeds to correspond with the machine settings. The substrate must be designed and processed to make the entire process feasible and reproducible.

Based on experiments run with the Series 17 , cutting power of 10 joule pulse per $\mathrm{mm}^{2}$ is required to produce stable end-of-life resistors. To assure complete removal of material, 120 pulses per mm should be used. In no case should less than 40 pulses per mm be used because an overlap of only $50 \%$ results at this rate, assuming a properly focused beam of $50 \mu \mathrm{m}$ in diameter.

Since the laser trimming process is basically a mechanical method for the removal of material, the less material there is to remove, the faster the process. Resistor thickness should be optimized and the screen printing and firing process should be controlled to assure reproducible results. If a resistor overglaze is used, this must be accounted for as additional material which must be removed, and the laser parameters must be adjusted accordingly.

\section{ACKNOWLEDGEMENTS}

The author wishes to acknowledge Ronald C. Headley for his valuable inputs and for his assistance in reviewing this manuscript.

Figures 1, 2 and 8 courtesy of Chicago Laser systems.

Figures 4, 5, 6 and 7 courtesy of Central Laser Corporation.

\section{BIBLIOGRAPHY}

R. T. Howard and R. V. Allen, Characterization of Laser Trimmed Thick Film Resistors by Scanning Electron Microscopy, Proceedings ISHM (1971).

R. C. Headley, M. J. Popowich and F. J. Anders, YAG Laser Trimming of Thick Film Resistors, IEEE Symposium (March, 1973).

R. E. Coté, R. C. Headley, J. T. Herman and A. Howe, Factors Affecting Laser-Trim Stability of Thick Film Resistors, Proceedings ISHM (1976).

J. R. Larry, M. J. Popowich, R. C. Headley and R. M. Rosenberg, A New High Stability Resistor System, Proceedings Electronic Components Conference (1977).

An Introduction to Laser Trimming, Chicago Laser Systems publication.

R. Conradt and L. S. Marcus, Thick Film Laser Trimming Principles, Techniques and Recommendations, Circuits Manufacturing (October, 1979).

Laser Trimming Throughput, Tetradyne publication (1978).

A. G. Albin and E. J. Swenson, Laser Resistor Trimming from the Measurement Point of View, Proceedings Electronic Components Conference (1971).

M. B. Davies, J. B. Willis and J. K. Wright, The Use of Lasers for Resistor Trimming, ISHM (UK) Conference (1971).

J. S. Shah and L. Berrin, Mechanism and Control of Past-Trim Drift of Laser Trimmed Thick Film Resistors, IEEE Transactions (June, 1978). 

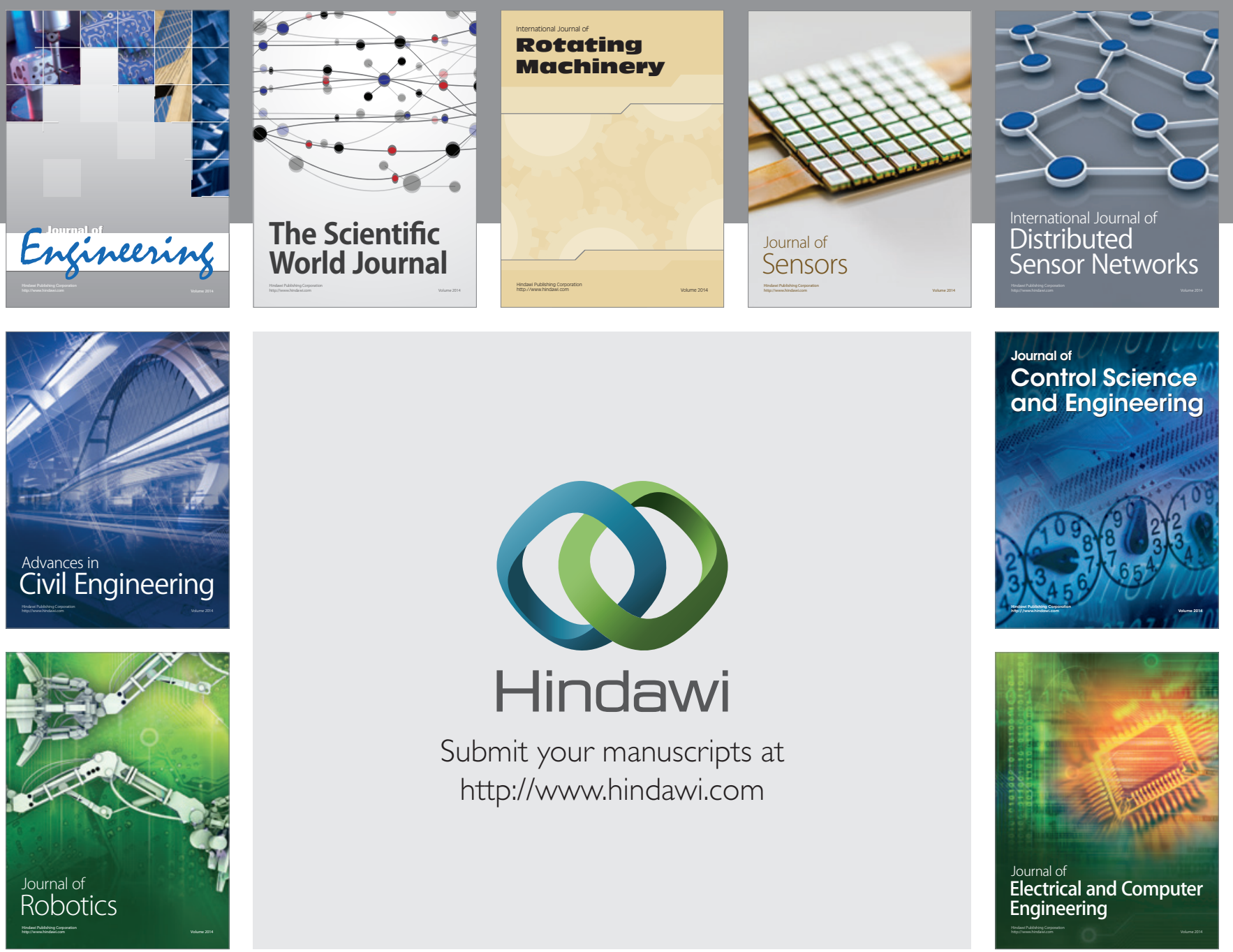

Submit your manuscripts at

http://www.hindawi.com
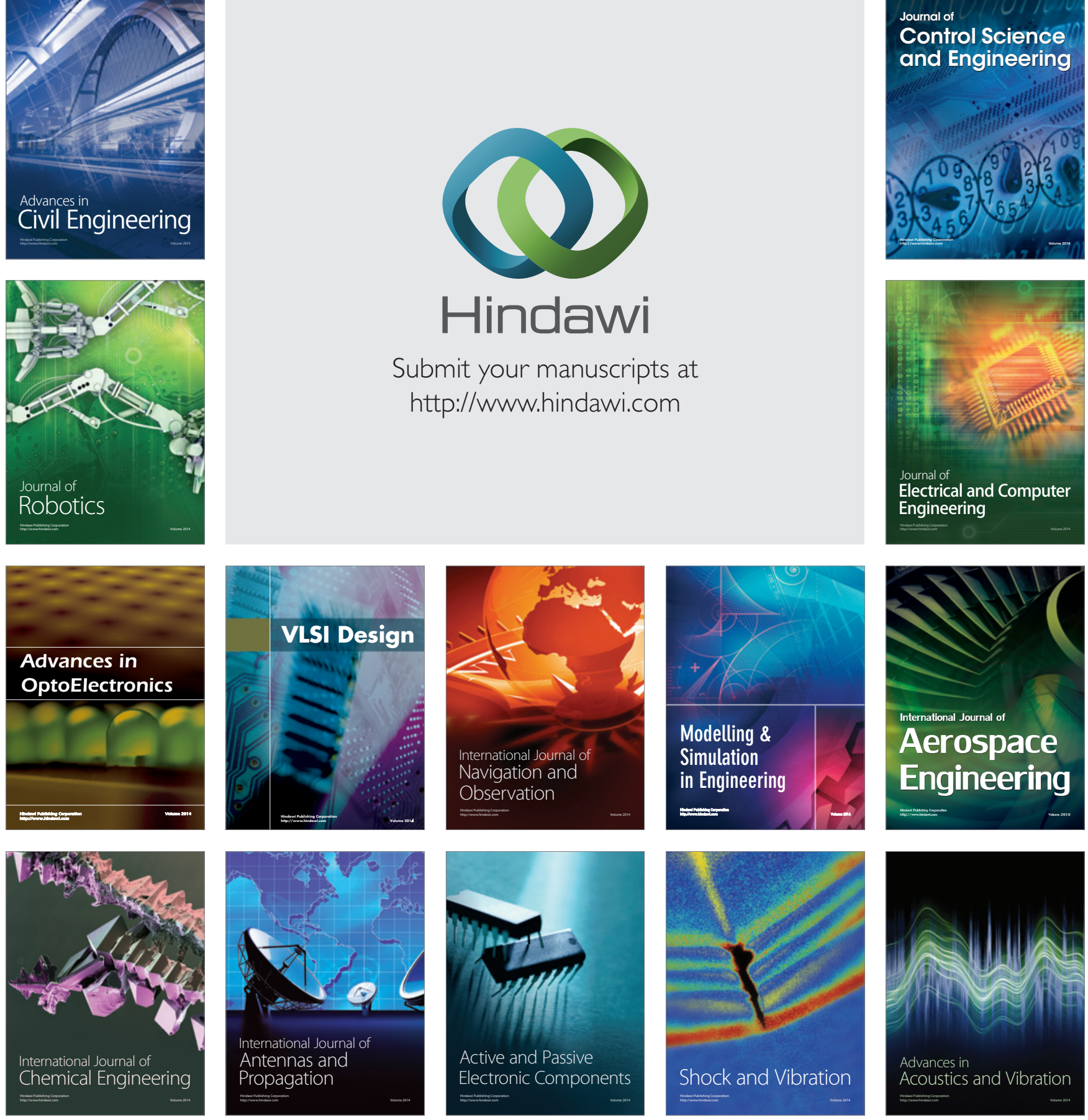